\title{
Recomendaciones conjuntas para el manejo clínico de la infección por SARS-CoV-2 y la enfermedad COVID-19. Versión 13 de marzo de 2020
}

\section{Elaboradas por integrantes de:}

Sociedad de Infectología Clínica del Uruguay (SICU).

Sociedad Uruguaya de Medicina Intensiva (SUMI).

Cátedra Enfermedades Infecciosas, Facultad de Medicina, Udelar.

Cátedra Medicina Intensiva, Facultad de Medicina, Udelar.

Sociedad Uruguaya de Emergencistas (SUE).

Sociedad de Medicina Interna del Uruguay.

Dpto. Medicina Familiar y Comunitaria, Facultad de Medicina, Udelar.

Sociedad Uruguaya de Medicina Familiar y Comunitaria (SUMEFAC).

Sociedad Uruguaya de Enfermería en Cuidados Intensivos (SUECI).

Clínica Médica C, Hospital de Clínicas, Udelar.

Sociedad Uruguaya de Neumología (SUN).

Asociación Latinoamericana para el Control de Infecciones (ASLACI).

Facultad de Enfermería, Udelar.

Departamento de Anestesiología, Hospital de Clínicas. Facultad de Medicina, Udelar.

Sociedad Uruguaya de Nefrología.

Centro de Nefrología, Hospital de Clínicas, Udelar.

Apoyo de:

Sociedad Uruguaya de Neonatología y Pediatría Intensiva.

Sociedad Integrada de Emergencia Pediátrica del Uruguay.

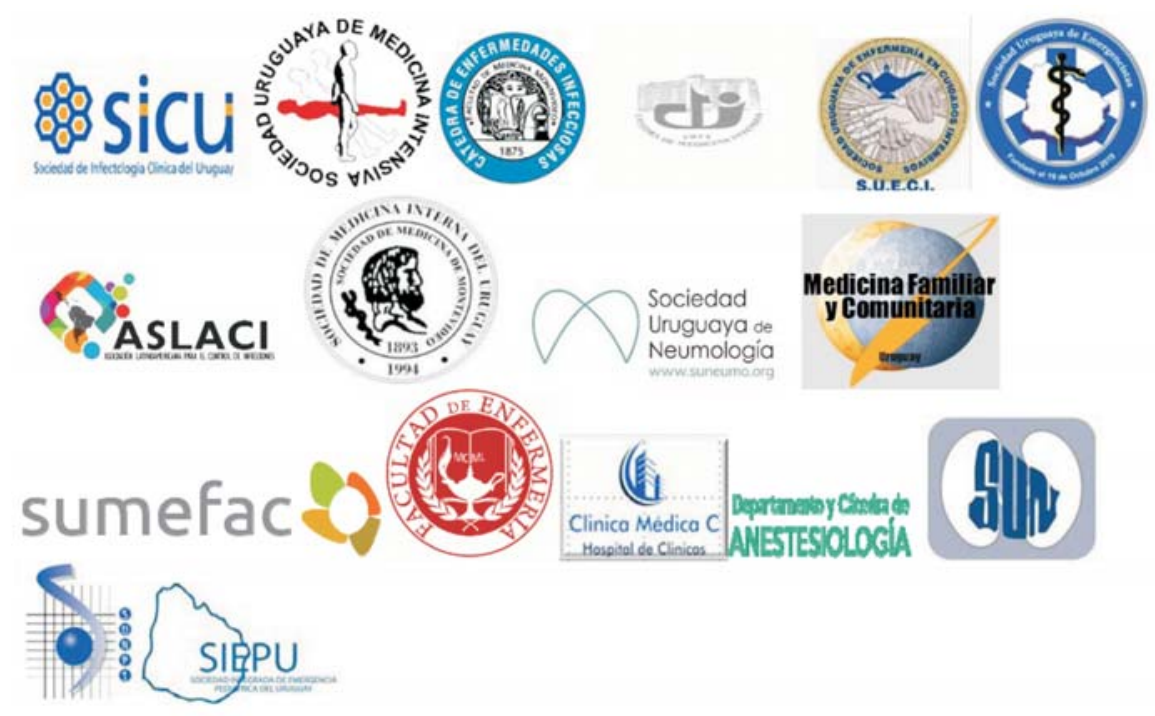




\section{Coordinación:}

Dra. Daniela Paciel. Especialista en Enfermedades infecciosas y Medicina intensiva. Integrante SICU y SUMI. Docente auxiliar Cátedra Enfermedades Infecciosas.

Dr. Luis Núñez. Presidente SUMI. Especialista en

Medicina intensiva. Magíster en Gestión de

\section{Participantes:}

Dr. Mauricio Bertullo. Especialista en Medicina intensiva y Gestión en servicios de salud. Mg. Control de la infección: Infecciones relacionadas con la atención sanitaria. Integrante de la SUMI. Dr. Gastón Burghi. Profesor Agregado de la Cátedra de Medicina intensiva. Facultad de Medicina, Udelar.

Dr. Manuel Baz. Prof. Clínica Médica C, Hospital de Clínicas.

Lic. Enf. Verónica Casanova, especialista en Cuidados intensivos y Administración de servicios de salud. Supervisora del Hospital de Clínicas, Facultad de Enfermería, Udelar. Integrante de la Sociedad Uruguaya de Enfermería en Cuidados Intensivos.

Dra. Victoria Frantchez. Especialista en Enfermedades infecciosas y Medicina interna. Integrante de SICU. Prof. Adj. de la Cátedra de Enfermedades Infecciosas, Facultad de Medicina, Udelar.

Lic. Enf. Álvaro Fernández. Especialista en Cuidados intensivos, en Quemados y en Administración de servicios de salud. Presidente de la Sociedad Uruguaya de Enfermería en Cuidados Intensivos.

Lic. Silvia Guerra. Epidemióloga. Especialista en Control de infecciones. Secretaria de la Asociación Latinoamericana para el Control de Infecciones (ASLACI).

Dr. Gonzalo Lacuesta. Especialista en Medicina intensiva. Coordinador CTI Hospital Policial. Dr. PhD. Julio Medina. Prof. de la Cátedra de Enfermedades infecciosas, Facultad de Medicina, Udelar.

Dra. Ana Mieres. Especialista en Medicina de emergencias, integrante de la Sociedad Uruguaya de Emergencistas. empresas de salud. Ex asistente de Cátedra de Medicina intensiva, Udelar.

Dr. Henry Albornoz. Presidente SICU. Especialista en Enfermedades infecciosas y Medicina intensiva. Prof. Adj. de la Cátedra de Enfermedades Infecciosas, Facultad de Medicina, Udelar.

Dra. Clara Niz. Prof. Agda. de Medicina Familiar y Comunitaria, Facultad de Medicina, Udelar. Integrante de la Sociedad Uruguaya de Medicina Familiar y Comunitaria (SUMEFAC).

Dra. Graciela Pérez. Especialista en Enfermedades infecciosas y Medicina interna. Docente adjunta honoraria, Cátedra de Enfermedades Infecciosas, Facultad de Medicina, Udelar.

Dr. Roberto Puñales. Anestesiólogo. Asistente del Departamento de Anestesiología. Hospital de Clínicas.

Dr. Martín Rebella. Especialista en Medicina interna. Prof. Adj. Clínica Médica, Hospital de Clínicas.

Dr. Juan Pablo Salisbury. Presidente de la Sociedad Uruguaya de Neumología. Especialista en Neumología.

Lic. Isabel Silva. Mag. Lic. Enf. Prof. Agda. Esp. Cuidados intensivos. Directora (s) Depto. Salud Adulto y Anciano. Facultad de Enfermería. Udelar. Dr. Ricardo Silvariño. Presidente de la Sociedad Uruguaya de Nefrología. Prof. Adj. Cátedra de Nefrología, Facultad de Medicina, Udelar. Dr. Juan Pablo Soto. Prof. Adj. Medicina intensiva. Ex asistente Neumología. Integrante de la Sociedad Uruguaya de Neumología.

Dr. Martín Yandian. Especialista en Medicina interna y Enfermedades autoinmunes. Integrante de la SMIU. Prof. Adj. de la Clínica Médica A.

Lic. Enf. Johanna Valecka. Especialista en Cuidados intensivos. Supervisora del Centro de Cuidados Especiales del HCFFAA. Integrante de la Sociedad Uruguaya de Enfermería en Cuidados Intensivos. 


\section{Introducción}

El mundo está enfrentando una enfermedad infecciosa emergente por un nuevo patógeno perteneciente a la familia de los coronavirus. En estos últimos meses el nuevo virus denominado SARS-CoV-2, causante de la enfermedad COVID-19, se ha expandido a nivel mundial con una transmisión muy eficiente y una tasa de letalidad mayor a la de la gripe estacional. El 30 de enero pasado, la Organización Mundial de la Salud (OMS) declaró esta situación como una Emergencia de Salud Pública de Importancia Internacional (PHEIC) y el 11 de marzo se declara como pandemia.

Actualmente, más allá del brote inicial en China, originado en Wuhan, han surgido brotes en otros países donde se evidencia una transmisión comunitaria sostenida, como en Irán, Italia, Japón, Francia, España, Alemania, Corea del Sur y Singapur. En el panorama actual se han diagnosticado casos en casi un centenar de países, incluidos países de la región.

En nuestro continente se prevé que la dispersión podría acelerarse en las próximas semanas.

El grupo de trabajo con integrantes de sociedades científicas y cátedras de la Facultad de Medicina de la Universidad de la República (Udelar) elaboró las actuales recomendaciones con el objetivo de complementar las directivas dadas a la población general, al personal sanitario y a los prestadores desde el Ministerio de Salud Pública (MSP) y organismos internacionales.

El documento contiene generalidades sobre COVID-19, medidas de prevención poblacional y en personal sanitario, además de recomendaciones para el manejo clínico de los pacientes. No se considera en estas recomendaciones el manejo de contactos durante el período de incubación, para ello sugerimos referirse al plan de contingencia del MSP. Sin embargo, recomendamos a aquellas personas asintomáticas que ingresen al país provenientes de aéreas con circulación sostenida o que hayan sido contacto de casos confirmados de COVID-19, que realicen cuarentena voluntaria por 14 días desde el contacto.

\section{Generalidades de SARS-CoV-2 y COVID-19}

El SARS-CoV-2 es un virus que está relacionado con el SARS-CoV y de allí su nombre y nomenclatura, compartiendo aproximadamente el $70 \%$ de su material genético. En función de estos hallazgos se plantea su origen en murciélagos. Los estudios realizados evidencian un número de mutaciones que apuntan a un ancestro común del que se estima que dio el salto al ser humano en noviembre de 2019. Si bien se han planteado diferentes huéspedes intermediarios, aún no se ha logrado confirmar uno en particular.
El período de incubación para la mayoría de las personas se ubica entre 4 a 7 días, pudiendo variar desde 1 a 14 días. Aún no está claro si las personas asintomáticas transmiten el virus, pero si lo hacen, probablemente la eficiencia en la transmisión sería muy baja.

Se ha demostrado la unión del virus al receptor ACE-2, que tiene un valor importante en la entrada del virus al huésped. No hay evidencia a la fecha de la implicancia terapéutica de este hallazgo.

Se ha establecido claramente la transmisión interhumana, estimándose una tasa de transmisión de dos a tres personas por cada caso confirmado (es lo que se refiere en diferentes publicaciones como el índice R0).

El mecanismo de transmisión es a través de gotitas y por contacto desde una persona sintomática o desde superficies contaminadas por el virus. En procedimientos médicos donde se generen aerosoles de partículas respiratorias la transmisión puede ser aérea.

Aún no está claro el tiempo de persistencia del virus en el ambiente, pero se sabe que las medidas de higiene ambiental y desinfección habituales son efectivas para bajar la carga de contaminación ambiental.

Los síntomas más frecuentes son fiebre, tos y disnea (dificultad para respirar). Algunos pacientes presentarán sintomatología respiratoria alta (resfrío, odinofagía) y en menor frecuencia puede haber síntomas gastrointestinales (dolor abdominal, diarrea, náuseas).

La mayoría de los pacientes que presentan formas graves de la enfermedad muestran una evolución en dos etapas, con una peoría progresiva a partir del octavo día, con desarrollo de insuficiencia respiratoria e imágenes radiológicas compatibles con neumonía "atípica" (infiltrados intersticio-alveolares bilaterales), pudiendo llegar a síndrome de distrés respiratorio (SDRA), shock y disfunción orgánica múltiple.

En función del brote en China, publicaciones procedentes de ese país han informado que aproximadamente el $80 \%$ de los casos tienen una presentación leve, $15 \%$ una presentación grave y $5 \%$ una presentación crítica.

El diagnóstico se basa en la clínica y el nexo epidemiológico que se actualiza a medida que se profundiza el conocimiento sobre la infección y su dispersión a nivel mundial. En función de las directivas dadas en nuestro país por el MSP, se procederá a la recolección de muestras y el envío de las mismas de acuerdo a los protocolos de actuación establecidos y disponibles en la página web del MSP. En nuestro país se dispone de técnicas de biología molecular (PCR-RT) en el Departamento de Laboratorio del MSP (DLSP). Los estudios disponibles hasta el momento, en algunos prestadores, para muestras respiratorias (por ejemplo, panel respiratorio FilmArray) identifican otros coronavirus y no el SARS-CoV-2. 
La letalidad global reportada de los casos es de 3,4\%. Otras especies de coronavirus, como el SARS-CoV y el Mers-CoV, han presentado letalidad de $9,5 \%$ y $34,5 \%$, respectivamente.

Los factores de riesgo para una mala evolución son la edad avanzada, enfermedades cardiovasculares y respiratorias crónicas, diabetes, inmunosupresión, entre otras.

El tratamiento es sintomático en los casos leves a moderados y de sostén de las funciones en los casos graves y críticos. Se están desarrollando varios ensayos con fármacos específicos, pero aún no hay datos concluyentes para recomendar un tratamiento en particular.

\section{Medidas de prevención}

\section{Para población general}

Se encuentran en estudio diferentes tipos de vacunas, pero aún no están disponibles. Al no contar con vacunas ni tratamiento específico, es de especial importancia la educación a la comunidad. Ésta se realizará en ámbitos asistenciales, comunitarios, educativos o laborales. Debe trabajarse en involucrar a la población, sensibilizar, desmitificar e informar sobre las medidas a aplicar con el fin de impedir la transmisión.

Dentro de las medidas más importantes se destacan:

1. Higiene de manos mediante el lavado con agua y jabón o fricciones con alcohol en gel, en forma frecuente, en particular luego de toser o estornudar. El uso de alcohol en gel puede sustituir el lavado de manos en caso que las mismas estén visiblemente limpias.

2. Evitar tocarse la cara y la mucosa de los ojos, la nariz o la boca.

3. Buena higiene respiratoria, es decir, al toser o estornudar hacerlo cubriendo la boca y fosas nasales con el pliegue del codo o utilizando pañuelos descartables.

4. Solo deben utilizar mascarillas las personas con síntomas respiratorios o aquellos que asistan a personas sintomáticas o con diagnóstico confirmado de la enfermedad.

5. Mantener una distancia de 1 a 2 metros con personas sintomáticas, no saludar con la mano, beso o abrazo; en el mismo sentido, evitar concurrir a sitios donde pueda haber aglomeraciones de personas.

6. No compartir utensilios de uso personal para bebidas y alimentos como sorbitos, vasos, cubiertos, mate, etc.

7. Mantener los ambientes ventilados y buena higiene de los mismos.
8. Evaluar los riesgos de viajes innecesarios a países o ciudades donde está ocurriendo transmisión sostenida (actualización en páginas oficiales).

9. Distanciamiento social voluntario con aislamiento y cuarentena de las personas sintomáticas.

10. Si comienza con síntomas y éstos son leves, se sugiere realizar la consulta médica en el domicilio, utilizar alternativas como la video consulta o la consulta médica telefónica de orientación, evitando concurrir a centros asistenciales; considere que en una situación de eventual sobredemanda de consultas, puede existir una demora en la evaluación médica de estos casos.

11. Además, se recomienda la vacunación anual para influenza y de ser necesaria la vacunación antineumocócica realizarla a los mayores de 65 años con comorbilidades y en particular si se trata de personal sanitario.

\section{Para personal sanitario}

Está indicado aplicar una correcta higiene de manos, así como las precauciones estándar, de contacto y por gotitas en la asistencia de los casos sospechosos y confirmados, y en caso de realizar procedimientos que generen aerosoles de partículas aplicar, además, precauciones respiratorias/aéreas.

Debe aplicarse higiene respiratoria y la etiqueta de la tos en los pacientes sintomáticos, incluyendo la colocación de mascarillas quirúrgicas a los que no requieran oxigenoterapia. Se recomienda que la espera sea la menor posible, en un área diferente a otros pacientes, para luego continuar la asistencia en habitación individual o en separación por cohortes, en áreas con ventilación adecuada.

El documento contiene recomendaciones específicas sobre el uso del equipo de protección personal (EPP) en cada escenario asistencial.

Como regla general, en todos los escenarios se recomienda:

- Provisión de EPP adecuados y capacitación para el uso de los mismos a fin de minimizar los riesgos de transmisión al personal sanitario.

- Todo trabajador de la salud debe comprender y poder cumplir con las recomendaciones para la prevención y control de infecciones.

- Siempre se debe realizar una adecuada higiene de manos antes de la colocación del EPP y luego del retiro de cada prenda.

- Los componentes descartables del EPP no deben ser reutilizados y deben ser descartados en el contenedor adecuado. 
- El personal que participa directamente en la asistencia y traslado debe contar con el EPP correspondiente que dependerá de las condiciones del paciente, a saber:

\section{EPP básico}

El EPP en este caso se compone de:

- Mascarilla quirúrgica.

- Cabello recogido (se recomienda el uso de gorro si el contacto con el paciente es prolongado en CTI, reanimación y en personal asignado a cohortes).

- Antiparras con protección lateral.

- Sobretúnica de manga larga (con adecuado puño elástico o enganche de pulgar) que cubra hasta pantorrilla, o mono integral, en ambos casos desechables y resistentes a la penetración por fluidos y por patógenos transmitidos por sangre. Si hay riesgo de contacto con fluidos corporales, se recomienda que la sobretúnica sea impermeable o en su defecto utilizar sobretúnica repelente a fluidos y delantal impermeable.

- Guantes no estériles resistentes a la tracción.

\section{EPP para procedimientos generadores de aerosoles}

- Gorro y cabello recogido.

- Mascarilla N95 (la misma podrá ser utilizada en más de un procedimiento generador de aerosoles por el mismo operador, debiendo para ello ser protegida en su cara externa durante su uso con mascarilla quirúrgica a descartar luego del mismo).

- Antiparras con sellamiento o máscara facial.

- Sobretúnica de manga larga (con adecuado puño elástico o enganche de pulgar) que cubra hasta pantorrilla, o mono integral, en ambos casos impermeables o en su defecto resistentes a la penetración por fluidos y por patógenos transmitidos por sangre y colocarse delantal impermeable por encima.

- Guantes no estériles resistentes a la tracción.

En los pacientes intubados y/o ventilados se recomienda:

- Colocar un filtro de alta eficiencia en la válvula espiratoria de la bolsa autoinsuflable (bolsa tipo ambú o similar).

- En los equipos de ventilación mecánica se debe colocar un filtro antimicrobiano de alta eficiencia en las ramas inspiratoria y espiratoria.

Las máscaras N95 o similares podrán utilizarse en más de una oportunidad, por el mismo usuario, si se asegura evitar un intercambio accidental y su conservación en condiciones adecuadas. No se recomienda un uso continuo de las mismas por un plazo superior a cuatro horas a fin de evitar lesiones de apoyo.

El EPP de material reutilizable podrá serlo luego de su adecuado procesamiento con los ciclos habituales de lavandería hospitalaria.

\section{Higiene ambiental y de equipos}

Se sugiere la limpieza del ambiente con agua y jabón y la desinfección con agentes de uso habitual (hipoclorito o cloro orgánico a una concentración de 1.000 ppm o alcohol al 70\%).

En cuanto a la higiene hospitalaria rutinaria, se recomienda aumentar la frecuencia de la misma, especialmente en superficies próximas al paciente y de alto contacto. Se recomienda cumplir con los protocolos institucionales y del MSP.

En aparatos de radiología móviles, salas de imagenología y otros centros de diagnóstico enfatizar la desinfección de superficies de alto contacto entre pacientes en forma rutinaria. Una opción para ello son toallas preimpregnadas en limpiador-desinfectante o toallas descartables con agregado de un limpiador desinfectante.

\section{Manejo clínico}

Las medidas recomendadas deben ser ajustadas al caso clínico individual y no deben sustituir el juicio clínico. A medida que se tenga más información y se profundice el conocimiento sobre esta enfermedad y su epidemiología, las mismas se irán actualizando.

En cuanto a la definición de caso sospechoso/confirmado referimos a la proporcionada por el MSP, considerando que la misma se irá actualizando de acuerdo a la situación mundial y local publicada en su página web.

Todo caso sospechoso debe ser notificado por vía telefónica y electrónica a la guardia de epidemiología del MSP (teléfono 1934 - 4010, las 24 horas) y al comité de infecciones de la institución (o referente institucional).

\section{Síndromes clínicos que se asocian a COVID-19 en adultos}

Infección viral no complicada del tracto respiratorio superior

Pueden presentar síntomas inespecíficos como fiebre, tos, odinofagia, conjuntivitis, congestión nasal, malestar general, cefalea, mialgias o astenia. Los ancianos y los inmunodeprimidos pueden presentar síntomas atípicos.

\section{Neumonía leve}

Paciente con neumonía y sin criterios de gravedad. 


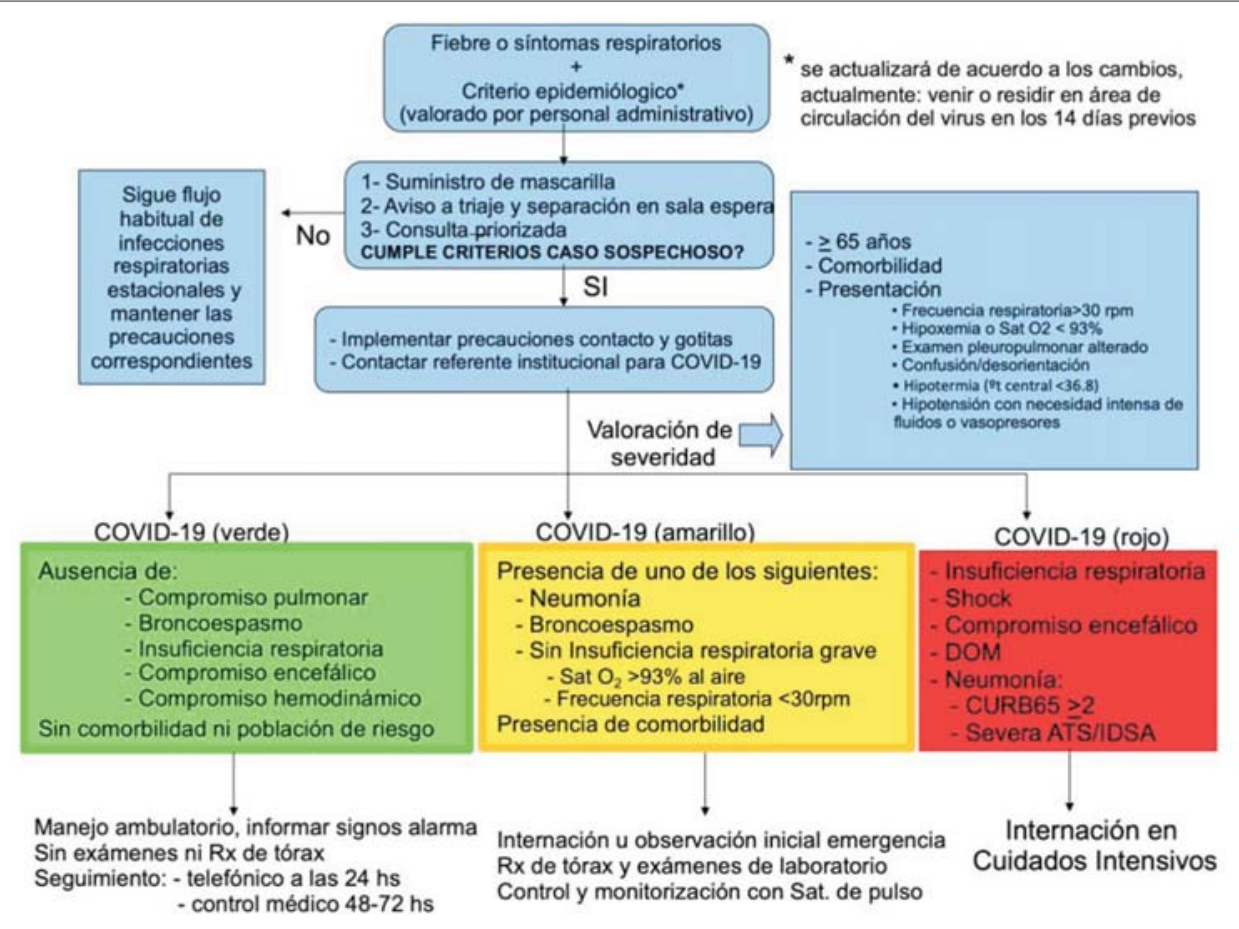

Figura 1. Flujograma de manejo clínico de caso sospechoso o confirmado de COVID-19

\section{Neumonía grave:}

Fiebre o sospecha de infección respiratoria, más una de los siguientes:

- Frecuencia respiratoria $>30$ respiraciones/min, distrés o $\mathrm{SpO}_{2}<90 \%$ ventilando espontáneamente al aire.

- Distrés (SDRA): según criterios de Berlín (2012).

- Sepsis: definición sepsis - 3 (2016).

- Shock séptico: definición sepsis - 3 (2016).

Tomado y adaptado de World Health Organization. Clinical management of severe acute respiratory infection when novel coronavirus ( $\mathrm{nCoV}$ ) infection is suspected: interim guidance. Published January 28, 2020. Accessed March 1st, 2020. https://www.who.int/publications-detail/clinical-management-of-severe-acute-respiratory-infection-when-novel-coronavirus-(ncov)-infection-is-suspected

\section{Evaluación de gravedad}

Siempre se debe utilizar el juicio clínico, que nunca es sustituido por las escalas de gravedad. En general, la gravedad en estos pacientes se desarrolla luego de los ocho días del inicio de los síntomas. Sugerimos que los pacientes con diagnóstico de neumonía por SARS$\mathrm{CoV}-2$, independientemente de la gravedad, sean eva- luados para hospitalizar y en caso de deterioro clínico el ingreso precoz a UCI.

Criterios de gravedad (ver flujograma):

- >65 años

- Comorbilidades

- Presentación clínica:

- Frecuencia respiratoria $>30 \mathrm{pm}$

- Hipoxemia o $\mathrm{SatO}_{2}$ menor a 93\%

- Examen pleuropulmonar alterado

- Confusión/desorientación

- Hipotermia (temperatura central <36,8)

- Hipotensión con requerimiento se sostén.

Los scores de gravedad recomendados para la estratificación son los siguientes:

- En caso de neumonía, escala de gravedad CURB-65 (C confusión aguda, Urea $>44 \mathrm{mg} / \mathrm{dL}$, R frecuencia respiratoria $\geq 30 \mathrm{RPM}, \mathrm{B}$ presión sistólica $\leq 90$ $\mathrm{mmHg}$ o diastólica $\leq 60 \mathrm{mmHg}$ y 65 edad $\geq 65$ ). Cada ítem puntúa 1 . Se sugiere evaluación para ingreso a CTI con puntuación $\geq 2$. En el ámbito extrahospitalario se emplea CRB-65.

- En caso de sospecha de sepsis, utilizar la escala SOFA: esta escala se utiliza en neumonía grave y/o sepsis, fundamentalmente para cuantificar el fallo de órganos y para seguimiento evolutivo. 
En la figura 1 se muestra el flujograma para estratificación y manejo del paciente.

\section{Medidas generales en la asistencia y manejo clínico inicial}

El manejo clínico inicial se guiará por la clasificación de gravedad según los criterios establecidos en el flujograma:

\section{1) Verde}

Los pacientes con enfermedad leve (no neumonía) que serán la mayoría, deben manejarse de forma ambulatoria y se sugiere que los mismos realicen la consulta en el domicilio. Se sugiere complementación entre los prestadores para la atención y el seguimiento de usuarios en domicilio cuando en una misma familia hay integrantes afiliados a distintos prestadores. Esta medida permite optimizar los recursos y disminuir el contacto con el personal sanitario Tienen fundamental importancia las medidas de prevención para evitar la transmisión intradomicilio y comunitaria cumpliendo con las medidas generales de prevención de la transmisión, detalladas más arriba en este documento, recomendadas por el MSP y publicadas en su página web.

El tratamiento se basa fundamentalmente en aliviar los síntomas en base a antipiréticos e hidratación. Se deben explicar claramente los signos de alarma y de reconsulta así como el circuito que debe seguir dentro de cada institución, evitando las consultas en puertas de emergencia y policlínicos.

Los elementos de reconsulta son: disnea, taquicardia, aumento del trabajo respiratorio, tendencia al sueño, cianosis, declinación funcional, etc. (elementos clásicos de peoría de infección respiratoria).

Es importante explicar y destacar que la peoría del estado clínico se presenta habitualmente a partir del octavo día del inicio de los síntomas.

Se sugiere control médico a las 24 horas (telefónico) y a las $48-72$ horas (presencial en domicilio en lo posible o mediante telemedicina), continuando con control cada 72 horas hasta 72 horas luego de resolución de síntomas.

Sugerir a los pacientes el autoaislamiento durante el período de la enfermedad, higiene de manos y personal adecuada, uso de mascarilla quirúrgica si está en contacto con otras personas a menos de 1 metro, y si por razones de extrema necesidad debe salir del domicilio, usar una mascarilla quirúrgica. Se sugiere seguir las recomendaciones del MSP.

\section{2) Amarillo}

En los pacientes que requieren hospitalización se deben garantizar adecuados niveles de prevención y control de la infección con el fin de proteger a los trabajadores sanitarios y evitar la propagación intrahospitalaria.

En líneas generales, el ingreso en sala de cuidados moderados será de preferencia en habitación individual o en casos confirmados en aislamiento por cohortes. Se debe limitar el número de personas que asisten al paciente intentando disminuir rotación, cumpliendo con el correcto uso del EPP. Asimismo, deben evitarse traslados innecesarios, y si se requieren para estudios o asistencia en otra unidad, éstos deben ser planificados y con circuitos preestablecidos (se detallan estos puntos más adelante en medidas generales en cuidados intensivos que aplican a todo traslado).

Los pilares del tratamiento serán: el control sintomático, la reposición de fluidos adecuada, tratamiento de eventuales comorbilidades y administración de antibacterianos y antivirales, como en toda neumonía comunitaria aguda, siguiendo las pautas institucionales y medidas generales que se deben aplicar.

La situación clínica del paciente debe ser monitorizada, y si se detectan criterios de gravedad, se valorará la necesidad de ingreso a UCI.

En pacientes con insuficiencia respiratoria debe iniciarse oxigenoterapia suplementaria mediante catéter nasal o máscara ajustando el flujo hasta alcanzar una saturación de oxígeno capilar adecuada a la edad y estado del paciente (en la mayoría de los casos la $\mathrm{SatO}_{2}$ objetivo será $\geq 93 \%$, en pacientes con EPOC la $\mathrm{SatO}_{2}$ objetivo será $\geq 90 \%$ ).

En caso de requerir tratamiento con broncodilatadores, se recomienda su administración en cartucho presurizado asociado a cámara espaciadora para evitar la generación de aerosoles (se recomienda evitar las nebulizaciones).

Deberá realizarse un manejo conservador de la fluidoterapia en pacientes con insuficiencia respiratoria aguda cuando no existe evidencia de shock.

No deben administrarse de forma rutinaria corticoides sistémicos para el tratamiento de la neumonía viral, a menos que éstos estén indicados por otra razón.

Se sugiere alta a domicilio cuando el paciente presente mejoría sintomática, en apirexia, sin taquicardia, sin polipnea, con adecuada saturación de pulso de acuerdo a la edad y a su condición clínica previa. Continuar seguimiento igual que en casos verdes.

\section{3) Rojo}

Los pacientes que presenten criterios de gravedad deberán ser evaluados para su ingreso temprano a UCI.

Las medidas de sostén deben implementarse en forma inmediata. 
- Si debe realizar intubación orotraqueal, aplicar un protocolo de intubación en secuencia rápida. Ver apartado Intubación orotraqueal más adelante.

- Realizar reposición de fluidos adecuada (balance neutro) e inicio de vasopresores en forma precoz (noradrenalina) de ser necesario.

- Realizar manejo según protocolo de tratamiento institucional.

- Recordar el uso adecuado del EPP al colocarse y al retirarse.

\section{Diagnóstico microbiológico y pruebas complementarias}

Las muestras para diagnóstico microbiológico pueden ser del tracto respiratorio superior: exudado nasofaríngeo y orofaríngeo, o del tracto respiratorio inferior: aspirado endotraqueal, especialmente en pacientes intubados.

Las muestras profundas parecen tener mayor rendimiento que las del tracto respiratorio superior especialmente en pacientes con neumonía y pueden ser obtenidas en casos de pacientes intubados con ventilación mecánica.

Si las pruebas iniciales son negativas en un paciente con una alta sospecha clínica y epidemiológica (especialmente cuando solo se han recogido muestras de tracto respiratorio superior o la muestra inicial no fue adecuada) se sugiere repetir muestras, idealmente del tracto respiratorio inferior y mantener medidas de prevención.

La vigilancia epidemiológica y el mecanismo de envío de muestras al DLSP se realizará de acuerdo al protocolo "COVID-19 vigilancia y diagnóstico laboratorial" MSP, actualizado al 9 marzo de 2020.

En los casos de neumonía o sepsis, o shock séptico, por su implicancia en el manejo realizar:

- Cultivos de secreciones respiratorias buscando otras causas de infección, coinfección o sobreinfección, y otros estudios para virus respiratorios (PCR para múltiples múltiples patógenos o similar), así como otros estudios microbiológicos y pruebas serológicas bacterianas o fúngicas.

- La detección de otros agentes etiológicos (gripe, VRS u otros) no descarta COVID-19, habiéndose descrito coinfecciones.

- Valorar otras posibles comorbilidades como VIH, hepatitis, etc.

Se recomienda una valoración analítica completa para evaluar disfunciones en pacientes catalogados como amarillos o rojos:

- Hemograma y crasis, bioquímica que incluya función renal, hepática, ionograma.
- Si sospecha insuficiencia respiratoria, gasometría arterial y lactato.

- Realizar estudios imagenológicos lo estrictamente necesario y evitar traslados innecesarios.

\section{Manejo prehospitalario}

Los equipos del primer nivel de atención, así como los de emergencia prehospitalaria juegan un rol fundamental en la detección precoz de casos sospechosos, triaje, asistencia inicial y en la definición de la necesidad y oportunidad de traslado de pacientes.

Si un usuario catalogado como caso sospechoso o confirmado de COVID-19 es asistido por una unidad de emergencia prehospitalaria se hace necesaria una comunicación efectiva y la coordinación con el prestador de salud de ese paciente a fin de acordar el ámbito donde continuará la asistencia según la situación clínica, contexto de cada persona afectada y recursos del prestador. Debe estar asegurada la continuidad asistencial.

Se proponen los siguientes pasos a seguir:

1. El personal sanitario debe colocarse el EPP básico previo al ingreso al domicilio siguiendo las recomendaciones.

2. Brindar al paciente mascarilla quirúrgica si su condición lo permite.

3. Clasificar según flujograma. En los casos catalogados como verdes (que permanecen en domicilio) debe asegurarse la continuidad asistencial con el prestador integral y realizar notificación obligatoria. El paciente que requiera traslado (amarillo o rojo), el mismo deberá ser realizado por una unidad de traslado especializada.

4. En caso de procedimientos que generan aerosoles, seguir las pautas de EPP recomendadas (RCP, intubación).

5. Si se decide realizar traslado previo, al inicio de éste se debe dar alerta al centro receptor para la toma de precauciones de control de infección adecuadas a adoptar ante el arribo del mismo y al coordinador/ jefe médico del servicio de emergencias médicas para que se efectúe la notificación correspondiente.

6. Realizar traslado siguiendo medidas de prevención y control del MSP.

7. Posteriormente al transporte del paciente, deberá seguirse las guías de desinfección y mantenimiento de los vehículos de transporte sanitario, basado en una limpieza del habitáculo, repisas y material, y posterior desinfección de las superficies y materiales reutilizables con paños o toallas descartables. 


\section{Manejo del paciente hospitalizado y del paciente crítico en UCI}

En este punto se tratan cuatro escenarios: a) Traslado intrahospitalario; b) Ingreso a UCI; c) Realización de procedimientos generadores de aerosoles (intubación oro/nasotraqueal), y d) Utilización de dispositivos específicos de asistencia.

\section{a) Traslado intrahospitalario}

El traslado de un paciente con COVID-19 supone un eventual riesgo de transmisión viral; por tanto, se deben seguir las medidas de protección y control que deben mantenerse durante el mismo, para evitar la diseminación de la infección.

Cada prestador deberá desarrollar un protocolo de traslado que se adecúe a sus instalaciones, que deberá ser de conocimiento de todos los participantes en la cadena de asistencia y traslado (personal médico, enfermería, camilleros, ascensoristas, personal de higiene, personal administrativo, usuarios), además se debe asegurar el suministro del material necesario para cumplir con el mismo. Se sugiere una cartelería acorde.

Como concepto general se deben minimizar todos los traslados que no sean estrictamente necesarios, hacerlos en forma programada previo a una adecuada comunicación entre los actores y asegurar mediante lista de chequeo la disponibilidad del EPP y las comunicaciones pertinentes.

Se debe establecer un circuito que debe incluir el traslado desde y hacia emergencia, unidad de cuidados intensivos, tomógrafo/resonador, block quirúrgico, entre otros. Este circuito no debe ser compartido en forma simultánea para el traslado de otros pacientes ni acompañantes. Las superficies que entren en contacto con el paciente o sus secreciones, o fluidos, deben posteriormente limpiarse y desinfectarse, antes de ser utilizadas por otros pacientes o trabajadores sanitarios. Se debe asegurar la desinfección de superficies tocables del ascensor, con énfasis en la botonera. De preferencia, educación del personal de traslado que debe evitar contactar superficies durante el traslado.

\section{b) Ingreso a hospitalización}

Se priorizan las habitaciones individuales para estos pacientes.

Se deberá contar con antesalas (con espacio suficiente para colocarse y quitarse el EPP) adyacentes a las salas de aislamiento (tanto individuales como cohortes). Si la sala no cuenta con antesala, se sugiere construir una antesala improvisada de material lavable.

El personal que asiste al paciente deberá ser el mínimo imprescindible. De ser posible, el personal de enfermería deberá ser exclusivo.
Todos los procedimientos a realizar se deben planificar a fin de minimizar la exposición (permanencia en la habitación, independientemente del tipo) de los trabajadores sanitarios.

Si es necesario, entrar en la habitación, pero no es necesario estar cerca del paciente; se mantendrá una distancia de 2 metros.

En el ingreso se deben distinguir los casos con sospecha de COVID-19 y los casos confirmados.

Pacientes con sospecha de COVID-2019, siempre que sea posible, deben ingresar a salas de aislamiento respiratorio de contar con las mismas, en habitación individual. Las puertas se deben mantener cerradas. Mantener ventilación adecuada.

Casos confirmados de COVID-2019: mismas consideraciones que para casos sospechosos. En caso de no disponer de habitaciones individuales, se pueden realizar aislamientos por cohortes.

\section{Condiciones particulares en los aislamientos por cohortes}

Implica compartir un área asistencial común manteniendo una distancia mínima de 2 metros entre los pacientes.

El personal que asiste a estos pacientes no debe asistir a pacientes que se encuentren fuera de la cohorte y se deberá evitar la rotación del personal asistencial.

Si un funcionario atiende la cohorte y hace guardia doble, debe continuar asistiendo a los mismos pacientes, evitando ir a otro sector.

\section{c) Realización de procedimientos invasivos y/o potencialmente generadores de aerosoles}

Todas las instituciones deberán elaborar un kit de EPP específico para la asistencia de pacientes con COVID-19. El mismo debe estar disponible en todas las áreas de las instituciones donde se asistan estos pacientes.

El kit debe contar con:

- dos sobretúnicas impermeables con las características descritas previamente,

- dos máscaras N95,

- dos gafas o máscaras con protección facial,

- dos gorros.

Si no incluye máscara con protección facial, siempre se deberá disponer de la misma para los casos de intubación y RCP.

Si no se dispone de sobretúnicas impermeables, se deben utilizar sobretúnicas repelentes a fluidos y delantal impermeable por la eventualidad del contacto con fluidos.

Todos los miembros del equipo de salud que participen en la realización de estos procedimientos, indepen- 
dientemente de su rol o número, deberán utilizar un EPP adecuado para una situación de generación de aerosoles.

Los procedimientos invasivos o potencialmente generadores de aerosoles integran un grupo heterogéneo que involucra desde prácticas habituales de cuidado y tratamiento hasta procedimientos menos frecuentes y en algunos casos excepcionales.

El riesgo del procedimiento para el personal sanitario está dado por el tipo de maniobra (por ejemplo, todas las que requieren un manejo directo de la vía aérea), así como la duración prolongada asistencial que pueda generar desconexión de vía aérea en pacientes intubados y ventilados.

\section{Procedimientos generadores de aerosoles}

- Intubación oro/nasotraqueal o cambio de la misma, o retiro.

- Traqueostomía: realización o cambio de sonda o decanulación.

- Ventilación con máscara con bolsa autoinsuflable.

- Aspiración de secreciones traqueobronquiales en pacientes que no tengan sistema de aspiración cerrado.

- Toma de muestras respiratorias profundas (aspirado traqueal).

- Drenaje pleural.

- Pacientes que se encuentren con VNI u OAF (de preferencia evitar).

- Fibrobroncoscopía.

- Nebulizaciones (de preferencia evitarlas y utilizar inhaloterapia con cámara y cartucho).

- Fisioterapia respiratoria (de preferencia evitar).

- Fibrogastroscopía en paciente ventilado (si requiere desinsuflación transitoria de neumotaponamiento).

- Ecocardiografía transesofágica (si requiere desinsuflación transitoria de neumotaponamiento).

- Reanimación cardiopulmonar (RCP).

- Ventilación en decúbito prono (VDP) dado el riesgo de desconexión de vía aérea.

En todas estas situaciones (excepto RCP y VDP) participará un operario (encargado de realizar el procedimiento) y un asistente.

En la RCP y en la VDP participarán 3 y 4 a 6 personas, respectivamente.

En el caso particular de la VDP, cada unidad debe contar o actualizar un protocolo para la realización de esta maniobra a fin de que se realice con la mayor seguridad, eficiencia y eficacia.

Valorar en cada caso si el procedimiento es imprescindible realizarlo de urgencia o se puede diferir. En los casos de procedimientos considerados como rutina (por ejemplo, aspiración de secreciones), los mismos tam- bién se deben individualizar y programar (por ejemplo, coordinar toma de muestras con el momento de la aspiración de la vía aérea) para asegurar una correcta implementación de las medidas de protección.

\section{Intubación orotraqueal/nasotraqueal}

\section{- Preparación}

1. Todos los procedimientos que involucran el manejo de la vía aérea son potencialmente generadores de aerosoles. La protección personal y la del resto del equipo son prioridad.

2. La intubación, de ser necesaria, siempre la debe realizar un profesional experto, de ser posible en los lugares predefinidos para esto (UCI, sector de la emergencia designado, etc.), tomando todas las precauciones para evitar la transmisión por vía aérea del virus.

3. Son necesarias solo dos personas para una intubación (el operario y un asistente). Se debe limitar al mínimo el número de asistentes a estos procedimientos.

4. Se recomienda contar con kits de EPP prearmados para intubación con todos los materiales necesarios para estos procedimientos para dos operadores.

5. Se recomienda realizar un check list (antes de iniciar el procedimiento, idealmente por un tercero) con los materiales a emplear para la maniobra, y también para la colocación y el retiro del EPP.

6. EPP necesario y orden de colocación correspondiente:
a) Gorro.
b) Mascarilla N95.
c) Protección facial (para el operario) / gafas con sellado (asistente).
d) Sobretúnica impermeable con característica des- critas previamente.
e) Doble par de guantes estériles.

7. Se recomienda especial cuidado con el manejo del laringoscopio, evitando dispersar las secreciones una vez utilizado. De preferencia, cubrirlo de inmediato con uno de los guantes externos.

8. Revisar la monitorización, acceso venoso, instrumentos, medicación, ventilador y sistema de aspiración a emplear.

- Procedimiento

9. Evite la intubación con fibrobroncoscopio a menos que esté específicamente indicado. No utilice anestésicos locales. Considere el uso de un videolaringoscopio en casos específicos, como una vía aérea difícil. Prever el uso de una guía de intubación.

10. Programe las alarmas y parámetros de la ventilación mecánica invasiva. 
11. Planifique la inducción de secuencia rápida (debe contar con un protocolo de acuerdo a los fármacos utilizados en su institución/unidad). Asegúrese de que un ayudante experimentado pueda realizar la presión cricoidea de ser necesaria. Es posible que deba modificar el protocolo de intubación de secuencia rápida en pacientes con un gradiente alveolar-arterial de $\mathrm{O}_{2}$ muy elevado, que se prevé no puedan tolerar 30 segundos de apnea, o aquellos con contraindicación de uso de succinilcolina.

12. Evite de ser posible la ventilación manual con máscara y bolsa autoinsuflable previo a la intubación. De ser necesario, utilizar volúmenes corrientes bajos, aumentando la frecuencia. De utilizarse, se hará con un filtro antimicrobiano de alta eficiencia entre la bolsa autoexpandible y la mascarilla, se deberá ventilar sellando bien para evitar fugas e hiperventilar.

13. De ser posible, realice cinco minutos de preoxigenación con mascarilla con reservorio de $\mathrm{O}_{2}$ (o con cánula nasal $\mathrm{O}_{2} 3 \mathrm{l} / \mathrm{min}$, manteniéndola durante la fase apneica) y posterior intubación de secuencia rápida.

\section{- Posprocedimiento}

14. Comprobar inmediatamente la posición correcta del tubo endotraqueal y asegurar su adecuada fijación.

15. Colocar un filtro hidrofóbico de alta eficiencia interpuesto entre el tubo y el ventilador o la bolsa autoinsuflable.

16. Conecte inmediatamente al paciente al ventilador, previa colocación de un sistema cerrado de aspiración de secreciones, el cual debe estar disponible en el momento de la intubación a fin de evitar desconexiones posteriores para su colocación.

17. Quítese el EPP dentro de un área designada. Se sugiere higiene de manos con alcohol gel entre la retirada de cada ítem que integra el EPP.

18. Considere todo el equipo usado en el manejo de la vía aérea y EPP como altamente contaminante. Descarte en forma adecuada y los que sean pasibles de reutilización deben colocarse en una bolsa de plástico y retirarse para su lavado y desinfección adecuada.

19. Luego del procedimiento se debe realizar higiene y desinfección de la unidad paciente con el desinfectante apropiado, según lo protocolizado en el centro asistencial.

20. Después de quitarse el equipo de protección, evite tocarse el cabello o la cara antes de la higiene de manos.

21. Todo el material de EPP es descartable a excepción de la protección facial y las antiparras que deberán procesarse como material contaminado, debiéndose proceder a su limpieza y desinfección luego de su uso.

\section{d) Utilización de dispositivos específicos de asistencia}

\section{Equipos de ventilación mecánica}

Todos los equipos de ventilación mecánica deben contar con un filtro antimicrobiano de alta eficiencia en las ramas inspiratoria y espiratoria, el cual debe ser cambiado según las especificaciones del fabricante.

Se emplearán humidificadores pasivos, con filtros de alta eficiencia, se evitará la humidificación activa.

Se debe utilizar de estar disponible, circuito cerrado de aspiración de vía aérea.

\section{Ventilación no invasiva (VNI), oxigenoterapia de alto flujo (OAF)}

Se desaconseja el uso de estas modalidades de soporte ventilatorio.

En los casos seleccionados en que se apliquen, se debe lograr un sellado adecuado de la interfase para evitar fugas, debiéndose emplear equipos de ventilación mecánica con doble tubuladura. Se deben evitar las desconexiones.

\section{Manejo del paciente crítico en UCI}

Se basa en el sostén de funciones en fallo y medidas de prevención de complicaciones vinculadas a la enfermedad y asistencia.

\section{Intubación orotraqueal (ver apartado correspondiente)}

La preoxigenación se debe realizar con mascarilla reservorio de $\mathrm{O}_{2}$.

Evitar máscara y bolsa autoinflable, en caso en que ésta deba utilizarse, se colocará un filtro antimicrobiano de alta eficiencia entre la bolsa autoinflable y la máscara (o entre la bolsa y la sonda de ventilación).

Procure optimizar el adecuado sellado de la misma para evitar fugas.

Evite hiperventilar. Se recomienda administrar bajos volúmenes corrientes, para lo cual se deberá chequear previamente el volumen de la bolsa autoinflable y no superar una frecuencia de $12 \mathrm{cpm}$.

Para la intubación orotraqueal se utilizarán preferentemente tubos endotraqueales con aspiración subglótica, y se conectará a un sistema de aspiración cerrado.

La premedicación estará orientada a lograr una adecuada relajación del paciente, evitando desencadenar el reflejo tusígeno (se recomienda aplicar un protocolo de intubación en secuencia rápida por un médico con amplia experiencia).

\section{Realización de exámenes con equipos portátiles}

Todo el equipamiento utilizado que no sea descartable, deberá ser limpiado y desinfectado según las recomendaciones del comité de infección de la institución. 


\section{Tratamiento de sostén y específico}

\section{Manejo hipoxemia}

La oxigenoterapia se inicia si la $\mathrm{SaO}_{2} \leq 93 \%$ aire ambiente con el objetivo de mantener $\mathrm{SaO}_{2} \geq 90 \%$. Los pacientes que ya reciben oxigenoterapia pueden evolucionar a un síndrome de distrés respiratorio agudo (SDRA) que se diagnosticará y clasificará según los criterios de Berlín.

Como paso inicial se utilizarán mascarillas con reservorio con flujos mínimos de 10 a $15 \mathrm{~L} /$ min para mantener el reservorio inflado y con $\mathrm{FiO}_{2}$ entre 0,60 y 0,95 .

Las cánulas OAF o la VNI deben reservarse para pacientes muy concretos, de ser posible deben ser evitadas, y evaluar una AVM invasiva precoz. Ambos sistemas (VNI y OAF) son generadores de aerosoles, además no se recomiendan en casos de inestabilidad hemodinámica y fallo multiorgánico, tampoco en los casos con hipercapnia (OAF).

En caso de utilizarse, se debe procurar que estos pacientes se encuentren en habitaciones individuales, con estricto monitoreo, y a fin de anticipar el deterioro y evitar una intubación de emergencia.

La endoscopía respiratoria debe reservarse para ocasiones excepcionales, como atelectasias con deterioro del intercambio gaseoso, y debe desalentarse como herramienta diagnóstica bacteriológica y de BK. Un aspirado traqueal convencional es suficiente.

\section{Ventilación mecánica invasiva (VMI)}

Se debe aplicar una estrategia de ventilación protectora, esto es: aplicar volúmenes corrientes bajos $(4 \mathrm{a} 6 \mathrm{~mL} / \mathrm{kg}$ de peso), evitar presiones plateau por encima de $30 \mathrm{~cm}$ de $\mathrm{H}_{2} \mathrm{O}$ y mantener una driving pressure (presión plateau-PEEP) por debajo de $15 \mathrm{~cm}$ de $\mathrm{H}_{2} \mathrm{O}$.

La analgosedación se deberá adecuar de tal forma que el paciente se encuentre adaptado a la VMI (evitar asincronías) y con un adecuado confort clínico. Solo si no se logra una adecuada adaptación con analgosedación o si el paciente se encuentra en decúbito prono, hay que asociar bloqueantes neuromusculares.

La titulación de la PEEP debe hacerse en función de la compliance, oxigenación, espacio muerto y estado hemodinámico.

Cuando la relación $\mathrm{Pa} / \mathrm{FIO} 2$, a pesar de una correcta optimización de la ventilación mecánica, es inferior a 150 , es necesario colocar al paciente en decúbito prono lo antes posible y ventilar al paciente en esta posición al menos 16 horas por día. La aplicación de esta estrategia requiere recursos humanos suficientes y experimentados para realizarla de forma segura. Se debe coordinar la entrada del personal a la unidad con cautela.

La ventilación en decúbito prono tiene, en general, una buena respuesta del punto de vista oximétrico y de la mecánica ventilatoria. Sin embargo, debemos considerar que para su realización son necesarias por lo menos cuatro personas para la rotación y una más para asegurar la sonda orotraqueal durante el procedimiento.

Deben tenerse preparadas de antemano las almohadas para los distintos puntos de apoyo: hombros, pelvis y tobillos, además de un dispositivo para sujetar la cabeza y permitir la ventilación mecánica.

Todo el procedimiento debe realizarse manteniendo las mismas precauciones de contacto que se venían manteniendo hasta el momento.

Se realizará en dos etapas: lateralización y pronación, manteniendo los cuidados necesarios para evitar la pérdida de dispositivos (tubos, catéteres, drenajes).

El brazo del lado del cual va a ser girado deberá colocarse bajo el hemicuerpo homolateral, el otro se reflexionará sobre el tórax.

Luego de pronado, el brazo sobre el cual va a ser girado quedará al costado del cuerpo y el otro quedará flexionado por encima del hombro con la cabeza mirando hacia el lado opuesto (posición de nadador).

La posición de la cama será en antitrendelemburg.

La cabeza y los brazos deberán rotarse de posición cada 4 horas.

Debe tener suma precaución con los puntos de apoyo de modo de evitar lesiones en los puntos de contacto.

Los balances hídricos deberán ser neutros para evitar el desarrollo de edema pulmonar y derrame pleural.

Se debe evitar la desconexión de la asistencia ventilatoria debido a que favorece la pérdida de la PEEP y el desarrollo de atelectasias. Deben utilizarse sistemas cerrados para aspirar la vía aérea y manejar la sonda orotraqueal.

\section{Diagnóstico de shock y tratamiento}

Cuando la presión arterial media sea igual o inferior a $65 \mathrm{mmHg}$ o el lactato sanguíneo sea igual o superior a 2 $\mathrm{mmol} / \mathrm{L}(18 \mathrm{mg} / \mathrm{dL})$ sin hipovolemia. En ausencia de mediciones de lactato los signos de hipoperfusión periférica (método de valoración de relleno capilar estandarizado), junto con la presión arterial media, se utilizarán para el diagnóstico.

Si persiste una presión arterial media igual o inferior a $65 \mathrm{mmHg}$, a pesar de la administración de líquidos, deben administrarse vasopresores (noradrenalina).

Actualmente se recomienda, tanto en la fase inicial como en el seguimiento de la resucitación, la valoración ecocardiográfica. Manejar los equipos siguiendo las recomendaciones de higiene y desinfección institucionales o del MSP, o ambas.

En caso de persistencia de shock y si se comprueba disfunción miocárdica asociada se aconseja administrar dobutamina. 


\section{Corticoides sistémicos}

No están recomendados de forma general. Estudios previos en pacientes con SARS, MERS e incluso gripe han demostrado que no tienen efectos beneficiosos e incluso se ha retrasado el aclaramiento del virus.

\section{Tratamiento antibiótico}

De tratarse de un paciente grave con planteo de NAC y/o sepsis respiratoria deberán iniciarse los tratamientos antimicrobianos pautados institucionalmente para estos cuadros, debiéndose además hacerlo en forma precoz en las primeras tres horas de asistencia y en caso de shock séptico en la primera hora.

En los casos confirmados de COVID-19 los antibióticos no están recomendados al inicio, aunque en función de la evolución y los resultados microbiológicos podrían ser necesarios.

En función de la evolución de los parámetros clínicos, analíticos y de los hallazgos microbiológicos, se debe considerar desescalar o escalar los tratamientos antimicrobianos que se hayan iniciado.

\section{Tratamiento antiviral específico}

Aún no hay evidencia de ensayos clínicos controlados para recomendar un tratamiento específico para el SARS-CoV-2, si bien hay varios estudios en marcha.

\section{Seguimiento y monitorización de la respuesta clínica}

Para los pacientes críticos se realizarán los controles habituales en forma horaria.

En la medida en que se logre la estabilidad, los controles se podrán espaciar.

En los pacientes que se encuentran hospitalizados en cuidados generales, se recomienda realizar un control de constantes vitales cada 4 - 6 horas.

En aquellos que se encuentren en domicilio y no presenten síntomas de gravedad, se realizará una vigilancia cada 24 - 72 horas, la cual puede ser presencial o por medios de comunicación, según las características del paciente, en particular comorbilidades.

\section{Alta del paciente}

Los casos en investigación en los que se descarte COVID-19 se guiarán por los criterios clínicos habituales. Previo al alta es imprescindible establecer comunicación con el nivel al que será referido el paciente. Se consideran valores de estabilidad generales: frecuencia cardíaca $<100 \mathrm{lpm}$, frecuencia respiratoria $<24 \mathrm{RPM}$, temperatura axilar $<37,2^{\circ} \mathrm{C}$, presión arterial sistólica $>$ $90 \mathrm{mmHg}, \mathrm{SaO}_{2}>90 \%$ si no había insuficiencia respiratoria previa, nivel de conciencia adecuado.

\section{Links consultados y sugeridos}

https://www.gub.uy/ministerio-salud-publica/comunicacion/noticias/comunicado-sobre-coronavirus-covid-19

https://www.gub.uy/ministerio-salud-publica/comunicacion/noticias/preguntas-frecuentes-medidas-proteccion-basicas-contra-nuevo-coronavirus

https:/www.cdc.gov/coronavirus/2019-ncov/hcp/guidance-for-ems.html

https://www.mscbs.gob.es/profesionales/saludPublica/ccayes/alertasActual/nCov-China/documentos/Protocolo_manejo_clinico_COVID-19.pdf

https://www.who.int/es/emergencies/diseases/novel-coronavirus-2019

https://www.thelancet.com/coronavirus?dgcid=kr_pop-up_tlcoronavirus 20

https://www.nejm.org/coronavirus

https://jamanetwork.com/journals/jama/pages/coronavirus-alert http://weekly.chinacdc.cn/

https://www.sadi.org.ar/coronavirus

https://www.esicm.org/resources/coronavirus-pu-

blic-health-emergency/

https://seimc.org/noticias/noticias-destacadas/detalle/4567/nuevo-coronavirus-sars-cov-2-y-covid-2019

https://www.cdc.gov/coronavirus/2019-ncov/index.html https://www.wfsahq.org/latest-news/latestnews/943-coronavirus-staying-safe

https://www.mscbs.gob.es/profesionales/saludPublica/ccayes/alertasActual/nCov-China/documentos/Manejo_primaria.pdf

\section{Bibliografía}

1. Lu H, Stratton CW, Tang YW. Outbreak of pneumonia of unknown etiology in Wuhan China: the mystery and the miracle. J Med Virol 2020; 92(4):401-2. doi:10.1002/jmv.25678.

2. Lu R, Zhao X, Li J, Niu P, Yang B, Wu H, Wang W, et al. Genomic characterization and epidemiology of 2019 novel coronavirus: implications for virus origins and receptor binding. Lancet 2020; 395(10224):565-74.

3. World Health Organization. Clinical management of severe acute respiratory infection infection when novel coronavirus (nCoV) infection is suspected: interim guidance. WHO, 28 january 2020. Disponible en: https:/www.who.int/publications-det ail/clinical-management-of-severe-acute-respiratory-infection-when-novel-coronavirus-(ncov)-infection-is-suspected [Consulta: $1^{\circ}$ marzo 2020].

4. Guan WJ, Ni ZY, Hu Y, Liang WH, Ou CQ, He JX, et al. Clinical characteristics of 2019 novel coronavirus disease 2019 in China. N Engl J Med 2020. doi: 10.1056/NEJMoa2002032. Disponible en: https://www.medrxiv.org/content/10.1101/2020.02.06.20020974v1.full.pdf [Consulta: 3 marzo 2020].

5. Qiu H, Tong Z, Ma P, Hu M, Peng Z, Wu W, et al. Intensive care during the coronavirus epidemic. Intensive 
Care Med 2020; 46(4):576-8. doi:10.1007/s00134-020-05966-y.

6. Organización Mundial de la Salud. Atención en el domicilio de pacientes presuntamente infectados por el nuevo coronavirus $(\mathrm{nCoV})$ que tengan síntomas leves y gestión de los contactos: orientaciones provisionales, 20 de Enero de 2020. OMS, 2020. Disponible en:

https://apps.who.int/iris/bitstream/hand- le/0665/330673/9789240000872-spa.pdf. [Consulta: $1^{\circ}$ marzo 2020].

7. Arabi YM, Fowler R, Hayden FG. Critical care management of adults with community-acquired severe respiratory viral infection. Intensive Care Med 2020; 46(2):315-28. doi: 10.1007/s00134-020-05943-5. 